\title{
FITOSSOCIOLOGIA DE PLANTAS DANINHAS EM CULTIVO DE AÇAIZEIRO
}

Ueliton Oliveira de Almeida ${ }^{1}$, Romeu de Carvalho Andrade Neto ${ }^{1,2}$, José Tadeu de Souza Marinho², Romário Rodrigues Gomes $^{1}$, João Ricardo de Oliveira ${ }^{1}$, Rayane Silva dos Santos ${ }^{3}$, Davair Lopes Teixeira Júnior ${ }^{1,4}$, Jamayra Conceição de Araújo ${ }^{1}$

\begin{abstract}
RESUMO - As plantas daninhas são consideradas como um dos principais problemas nas culturas, pois interfere no rendimento, qualidade do produto e na rentabilidade da atividade agrícola. O adequado manejo destas plantas depende, primeiramente, da identificação das espécies presentes na área. O levantamento fitossociológico é uma importante ferramenta para auxiliar na escolha do melhor método de controle e quando realizá-lo. O objetivo deste estudo foi realizar levantamento fitossociológico de plantas daninhas em monocultivo de açaizeiro solteiro no município de Rio Branco, Acre. O estudo foi realizado no campo experimental da Embrapa Acre em março de 2014. As amostragens foram realizadas com um quadrado de madeira de $0,25 \mathrm{~m}^{2}(0,50 \times 0,50 \mathrm{~m})$, o qual foi lançado ao acaso por doze vezes em toda a área. As plantas daninhas foram quantificadas e identificadas quanto à classe, família, espécie, nome comum, tipo de propagação, hábito de crescimento e o respectivo ciclo de vida, além dos seguintes parâmetros fitossociológicos: densidade absoluta (D), densidade relativa (DR\%), abundância absoluta (A), abundância relativa (AR\%), frequência absoluta (F), frequência relativa (FR\%), importância relativa (IR\%) e o índice de valor de importância (IVI). Identificou-se 34 espécies distribuídas em 13 famílias, destacando-se as famílias Poaceae, Cyperaceae e Asteraceae, com 11, 6 e 3 espécies, respectivamente. A classe das dicotiledôneas apresentou o maior número de famílias (76,92\%) enquanto que a das monocotiledôneas representou a maior quantidade das espécies (55,88\%). A maioria das espécies observadas propagam-se por sementes, apresentam hábito de crescimento herbáceo e ciclo de vida anual. As espécies mais importantes foram Digitaria sanguinalis e Mollugo verticillata, pois se destacaram em todos os parâmetros fitossociológicos analisados.
\end{abstract}

Palavras chave: comunidade infestante, Euterpe precatoria Mart., monocultura.

\section{PHYTOSOCIOLOGY OF WEEDS IN AÇAÍ PALM CROP}

\begin{abstract}
Weeds are considered one of the main problems in crops, as it interferes with yield, product quality and profitability of agricultural activity. The proper management of these plants depends, first, on the identification of the species present in the area. The phytosociological survey is an important tool to assist in choosing the best method of control and when to carry it out. The objective of this study was to perform a phytosociological survey of weeds in single acai monoculture in the city of Rio Branco, Acre. The study was carried out at the Embrapa Acre experimental field in March 2014. Samples were taken with a $0.25 \mathrm{~m}^{2}(0.50 \times 0.50 \mathrm{~m})$ square of wood, which was randomly cast twelve times the entire area. The weeds were quantified and identified according to class, family, species, common name, propagation type, growth habit and their life cycle, in addition to the following phytosociological parameters: absolute density $(D)$, relative density (DR\%), absolute abundance $(A)$, relative abundance $(A R \%)$, absolute frequency $(F)$, relative frequency (FR\%), relative importance (IR\%) and importance value index (IVI). It was identified 34 species
\end{abstract}

\footnotetext{
${ }^{1}$ Engenheiro Agrônomo (a) do Programa de Pós-Graduação em Agronomia da Universidade Federal do Acre, BR 364, Km 04, Distrito Industrial, CEP 69.920-900, Rio Branco-AC. E-mail para correspondência: uelitonhonda5@hotmail.com.

${ }^{2}$ Pesquisador (a) da Embrapa Acre, BR 364, Km 14, CEP 69.908-970, Rio Branco-AC.

${ }^{3}$ Graduanda em Engenharia Agronômica pela Universidade Federal do Acre, BR 364, Km 04, Distrito Industrial, CEP 69.920-900, Rio Branco-AC.

${ }^{4}$ Docente do Instituto Federal do Acre. Campus Xapuri. Rua Coronel Brandão, no 1.622, Centro, CEP: 69.930-000.
} 
distributed in 13 families, standing out the families Poaceae, Cyperaceae and Asteraceae, with 11, 6 and 3 species, respectively. The dicotyledonous class presented the largest number of families (76.92\%) while the monocotyledonous class represented the largest number of species (55.88\%). Most of the species observed are propagated by seeds, present herbaceous growth habit and annual life cycle. The most important species were Digitaria sanguinalis and Mollugo verticillata, as they stood out in all phytosociological parameters analyzed.

Keywords: Euterpe precatoria Mart., monoculture, weed community.

\section{INTRODUÇÃO}

A espécie Euterpe precatoria Mart, conhecida como açaizeiro solteiro, é uma palmeira pertencente à família Arecaceae, com origem na região amazônica. Após o processamento de seus frutos, obtém-se a polpa, principal produto de valor econômico da planta, a qual possui fontes de minerais, como antocianinas e ácidos graxos importantes para a dieta do homem (Yuyama et al., 2011). Além de ser saboroso e refrescante, o açaí é uma fruta com valor nutricional altamente energético, contendo elevado teor de lipídios, carboidratos, proteínas, tornando-o como alimento calórico (Cedrim et al., 2018).

Na produção do açaí, assim como qualquer outra espécie agrícola, ocorre diversos fatores bióticos ou abióticos que afetam a qualidade e o rendimento da cultura, bem como a rentabilidade da atividade. Dentre os fatores bióticos, as plantas daninhas são consideradas como um dos principais problemas na produção agrícola, pois interferem no crescimento e desenvolvimento das culturas, sendo necessário realizar o adequado manejo delas para obter boas produtividades. As espécies Euterpe precatoria e Euterpe oleracea possuem crescimento inicial lento após o transplantio (Vieira et al., 2018; Almeida et al., 2019), e com isso, favorece o estabelecimento de plantas daninhas, já que o solo permanece descoberto por um período relativamente longo. Conforme Melo (2018), a competição das plantas daninhas nos períodos iniciais da cultura pode ser mais intensa devido ao crescimento lento da espécie cultivada, o que pode resultar na redução do seu crescimento e desenvolvimento.

A interferência das plantas daninhas com a cultura ocorre por meio da competição por água, luz, nutrientes e gás carbônico, e ainda podem liberar substâncias alelopáticas no solo que podem influenciar no desenvolvimento da cultura, além de atuarem como hospedeiras de pragas e doenças (Moura Filho et al., 2015; Almeida et al., 2018).
A identificação das espécies de plantas daninhas é uma das primeiras etapas para um adequado manejo, especialmente daquelas que apresentam maior importância na estrutura da comunidade infestante. As informações prévias referentes à biologia das espécies presentes na área de cultivo de qualquer cultura, tais como forma de propagação, hábito de crescimento, ciclo de vida, bem como o tipo de folha, larga ou estreita, são necessárias para auxiliar na escolha do método de controle a ser utilizado (Oliveira \& Freitas, 2008; Albuquerque et al., 2012; Teixeira Júnior et al., 2017; Almeida et al., 2018).

Para isso, é necessário realizar o levantamento fitossociológico seguido da identificação das espécies. Este levantamento é fundamental para o adequado manejo, pois fornece informações tanto da biologia das plantas daninhas quanto dos parâmetros fitossociológicos de densidade, frequência, abundância, importância e distribuição na área de produção (Oliveira \& Freitas, 2008; Albuquerque et al., 2012). Segundo Ferreira et al. (2019), a identificação de espécies infestantes é importante, pois os prejuízos ocasionados pela competição dependem das espécies envolvidas, da densidade de populações e do seu estádio de desenvolvimento.

Os índices do levantamento fitossociológico confrontam as populações de plantas daninhas em um deliberado tempo e espaço, visando determinar de forma hierárquica as espécies em função da sua posição relativa às demais, dentro das áreas com culturas agrícolas (Martins et al., 2018), uma vez que cada espécie apresenta agressividade e danos diferenciados entre as culturas. Na literatura, há estudos fitossociológicos com diversas culturas, desde anuais a perenes, e em sistemas de cultivo diferenciados como monocultivos, consórcios e sistemas agroflorestais. Entretanto, para o açaizeiro existem poucas informações, o que reforça a importância de estudos quanto a identificação das espécies de plantas daninhas presentes nesta cultura. Dessa forma, objetivou-se com este trabalho realizar o levantamento fitossociológico de plantas daninhas em monocultivo de açaizeiro solteiro em Rio Branco, Acre. 


\section{MATERIAL E MÉTODOS}

O levantamento fitossociológico foi realizado no campo experimental da Embrapa Acre, em Rio Branco-AC. O clima da região, conforme a classificação de Köppen-Geiger, é do tipo Am, equatorial, quente e úmido, com temperaturas médias anuais do ar variando de $24,5{ }^{\circ} \mathrm{C}$ a $32{ }^{\circ} \mathrm{C}$, umidade relativa do ar média de $83 \%$, precipitação pluviométrica anual de $1.648,9 \mathrm{~mm}$, e com estações seca e chuvosa bem definidas.

O solo da área foi classificado como Argissolo Vermelho-Amarelo distrófico de textura média e bem drenado, sendo os atributos físico-químicos dispostos na Tabela 1, e os dados climáticos entre o plantio (novembro/2013) e a realização do levantamento fitossociológico (março/2014) na Figura 1.

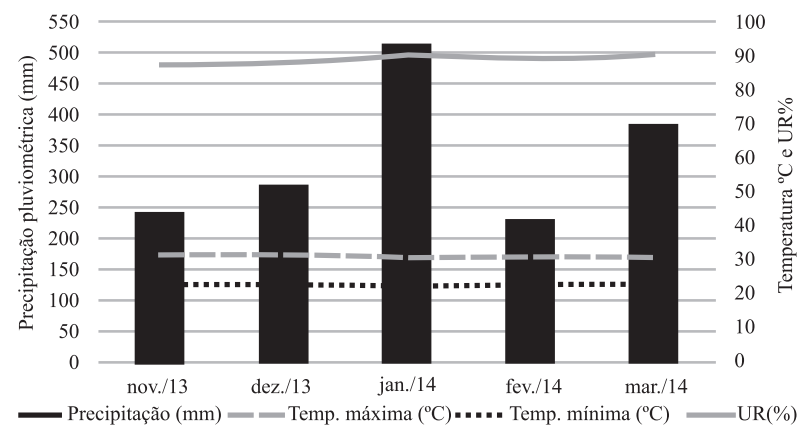

Figura 1 - Dados meteorológicos registrados entre o plantio de açaizeiro solteiro e o levantamento fitossociológico das plantas daninhas. Rio Branco, AC.

Tabela 1 - Atributos físico-químicos da área utilizada no cultivo de açaizeiro em Rio Branco, AC

\begin{tabular}{|c|c|c|c|c|c|c|c|c|c|c|}
\hline \multirow{2}{*}{ Camada (cm) } & $\mathrm{pH}$ & $\mathrm{Ca}$ & $\mathrm{Mg}$ & $\mathrm{K}$ & $\mathrm{Al}+\mathrm{H}$ & $\mathrm{P}$ & SB (\%) & Areia & Silte & Argila \\
\hline & \multicolumn{5}{|c|}{--------cmol $\mathrm{dm}^{-3}$-------- } & \multicolumn{2}{|l|}{$\mathrm{mg} \mathrm{L}^{-1}$} & \multicolumn{3}{|c|}{------------g kg-1------------ } \\
\hline $0-20$ & 4,52 & 1,40 & 0,79 & 0,32 & 4,43 & 9,91 & 36,18 & 315,42 & 319,88 & 364,70 \\
\hline $20-40$ & 4,60 & 0,85 & 0,54 & 0,20 & 4,91 & 4,21 & 24,53 & 388,66 & 329,25 & 282,10 \\
\hline
\end{tabular}

O levantamento fitossociológico foi realizado em uma área de experimento de açaizeiro solteiro, o qual foi implantado no espaçamento de 4 x 3 m (833 plantas ha-1), em covas de 0,4 x 0,4 x 0,4 m, previamente preparadas com adubação química e orgânica recomendadas para o açaizeiro de touceira (Euterpe oleracea Mart.) mediante análise de solo e com 30 dias de antecedência. O manejo das plantas daninhas foi realizado com capinas manuais mensalmente no período das chuvas, e posteriormente foi feito com roçadeira costal, sendo o último controle realizado aos 40 dias antes da realização do levantamento fitossociológico, tempo necessário para emergência das espécies infestantes. O cultivo foi conduzido sem uso de irrigação suplementar.

Aos quatro meses após o plantio foram realizadas as amostragens das plantas daninhas utilizando-se um quadrado de madeira de $0,25 \mathrm{~m}^{2}(0,50 \times 0,50 \mathrm{~m})$, o qual foi lançado doze vezes ao acaso por meio de caminhamento em ziguezague em toda a área de cultivo, correspondente a 0,072 ha $\left(720 \mathrm{~m}^{2}\right)$. As espécies foram coletadas, cortadas ao nível do solo, e identificadas quanto à classe, família, espécie, nome comum, tipo de propagação, hábito de crescimento e o respectivo ciclo de vida através de comparações na literatura de fotos e descrições ((Kissmann \& Groth, 1997; Lorenzi, 2008).
A identificação e contagem das plantas em cada ponto de amostragem permitiu calcular os seguintes parâmetros fitossociológicos: densidade absoluta (D), abundância absoluta (A), frequência absoluta $(\mathrm{F})$, densidade relativa (DR\%), abundância relativa (AR\%), frequência relativa (FR\%), importância relativa (IR\%) e o índice de valor de importância (IVI). Os cálculos foram realizados conforme as seguintes fórmulas (Moura Filho et al., 2015; Almeida et al., 2018; Martins et al., 2018; Carmo et al., 2019; Ferreira et al., 2019; Witter et al., 2019):

$$
\begin{aligned}
& D=\frac{\text { número total de indivíduos por espécie }}{\text { número de quadrados obtidos (área total) }} \\
& A=\frac{\text { número total de indivíduos por espécie }}{\text { número de quadrados que contém a espécie }} \\
& F=\frac{\text { número de quadrados que contém a espécie }}{\text { número de quadrados obtidos (área total) }} \\
& D R \%=\frac{\text { densidade da espécie } x 100}{\text { densidade total de todas as espécies }} \\
& A R \%=\frac{\text { abundância da espécie } x 100}{\text { abundância total de todas as espécies }} \\
& F R \%=\frac{\text { frequência da espécie } x 100}{\text { frequência total de todas as espécies }} \\
& I R \%=\frac{\text { índice de valor de importância da espécie } x 100}{\text { índice de valor de importância de todas as espécies }} \\
& I V I=\text { DR\% }+ \text { AR\% }+ \text { FR } \%
\end{aligned}
$$




\section{RESULTADOS E DISCUSSÃO}

O levantamento fitossociológico da comunidade infestante apresentou a ocorrência de 34 espécies de plantas daninhas distribuídas em 13 famílias, destacando-se às dicotiledôneas com dez famílias (76,92\%). Por outro lado, a classe das monocotiledôneas representou o maior número de espécies, com $55,88 \%$, enquanto que a dicotiledônea apresentou 44,12\%.

AsprincipaisfamíliasocorridasnaáreaforamPoaceae, CyperaceaeeAsteraceae,com11,6e3espécies, correspondendo

Tabela 2 - Identificação da comunidade infestante em monocultivo de açaizeiro solteiro. Rio Branco-AC, 2014

\begin{tabular}{|c|c|c|c|c|c|c|}
\hline Classe & Família & Espécie & Nome comum & Tipo de propagação & Hábito de crescimento & Ciclo de vida \\
\hline \multirow{15}{*}{ 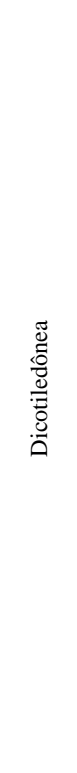 } & Amaranthaceae & Alternanthera tenella & manjericão & sementes & prostrada ou ascendente & anual ou perene \\
\hline & \multirow{3}{*}{ Asteraceae } & Corchorus olitorius & Melouquiá & sementes & ereta, herbácea ou sublenhosa & Anual \\
\hline & & Emilia coccinea & serralhinha & sementes & herbácea & Anual \\
\hline & & Praxeliz pauciflora & mata-pato & sementes & herbácea & Anual \\
\hline & Euphorbiaceae & Acalypha arvensis & rabo-de-gato & sementes & ereta & Anual \\
\hline & \multirow{2}{*}{ Fabaceae } & Pueraria phaseoloides & Puerária & sementes & herbácea, trepador & perene \\
\hline & & Desmodium adscendens & Carrapicho & sementes & herbácea, prostrada & perene \\
\hline & Loganiaceae & Spigelia anthelmia & pimenta-da-água & sementes & ereta, herbácea & Anual \\
\hline & \multirow{2}{*}{ Malvaceae } & Malva sp. & Malva & sementes & subarbustiva & Anual \\
\hline & & Anoda cristata & malva-de-crista & sementes & herbácea & anual \\
\hline & Molluginaceae & Mollugo verticillata & capim-tapete & sementes & $\begin{array}{l}\text { prostrada ou decumbente/ } \\
\text { herbácea }\end{array}$ & Anual \\
\hline & \multirow[b]{2}{*}{ Phyllanthaceae } & Phyllanthus niruri & quebra-pedra-branco & sementes & ereta, ramificada/herbácea & Anual \\
\hline & & Phyllanthus tenellus & quebra-predra & sementes & $\begin{array}{c}\text { ereta, ramificada/ pouco } \\
\text { herbácea }\end{array}$ & Anual \\
\hline & Plantaginaceae & Lindernia dubia & $\begin{array}{c}\text { agriãozinho-tapete- } \\
\text { da-água }\end{array}$ & sementes & herbácea & anual ou perene \\
\hline & Rubiaceae & Spermacoce latifolia & erva-quente & sementes & $\begin{array}{c}\text { prostrada ou ascendente, } \\
\text { herbácea }\end{array}$ & Anual \\
\hline \multirow{17}{*}{ 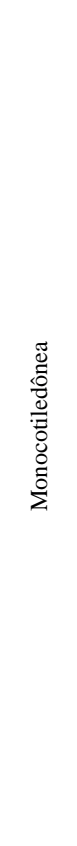 } & \multirow{2}{*}{ Commelinaceae } & Commelina benghalensis & Trapoeraba & sementes & semi-prostrada & perene \\
\hline & & Murdannia nudiflora & trapoerabinha & sementes & herbácea & Anual \\
\hline & \multirow{6}{*}{ Cyperaceae } & Cyperus sp. & Tiririca & sementes & herbácea & perene \\
\hline & & Cyperus esculentus & Tiriricão & sementes e rizomas & ereta, herbácea & perene \\
\hline & & Cyperus iria & Tiririca & sementes & ereta, herbácea, cespitosa & Anual \\
\hline & & Fimbristylis dichotoma & falso-alecrim-da-praia & sementes e rizomas & ereta, herbácea e entouceirada & anual ou perene \\
\hline & & Kyllinga odorata & capim-santo & sementes e rizomas & ereta, cespitosa, herbácea & perene \\
\hline & & Rhychospora nervosa & tiririca-branca & sementes & ereta e herbácea & perene \\
\hline & \multirow{9}{*}{ Poaceae } & Brachiaria brizantha & braquiária & sementes e rizomas & cespitosa & perene \\
\hline & & Brachiaria decumbens & braquiária & sementes e rizomas & $\begin{array}{l}\text { ereta ou decumbente, } \\
\text { entouceirada }\end{array}$ & perene \\
\hline & & Digitaria bicornis & capim-colchão-tropical & sementes & herbácea, subereta & Anual \\
\hline & & Digitaria horizontalis & capim-colchão & sementes & $\begin{array}{l}\text { herbácea, ereta ou } \\
\text { decumbente }\end{array}$ & Anual \\
\hline & & Digitaria sanguinalis & capim-colchão & sementes & $\begin{array}{l}\text { herbácea, decumbente e } \\
\text { entouceirada }\end{array}$ & perene \\
\hline & & Eleusine indica & capim-pé-de-galinha & sementes & ereta, entouceirada & anual ou perene \\
\hline & & Leptochloa filiformis & capim-mimoso & sementes & ereta, herbácea & Anual \\
\hline & & Panicum maximum & capim-colonião & sementes e rizomas & robusta, entouceirada & perene \\
\hline & & Paspalum conjugatum & capim-azedo & sementes e rizomas & robusta, entouceirada & perene \\
\hline
\end{tabular}


a 32,35\%, 17,65\% e 8,2\% do total de espécies, respectivamente e as demais apresentaram uma ou duas espécies (Tabela 2). Dentre a classe das monocotiledôneas, a família Poaceae foi a mais representativa, com 57,89\%, seguida da Cyperaceae com $31,58 \%$, enquanto que o maior número de espécies dentro das dicotiledôneas foi encontrado com à família Asteraceae, com 20\%, seguida da Fabaceae, Malvaceae e Phyllanthaceae, ambas com 13,33\% das espécies.

Almeida et al. (2018), ao realizarem levantamento fitossociológico de plantas daninhas na cultura da bananeira em diferentes espaçamentos de plantio, em área de cultivo próxima ao do presente estudo, também observaram que as famílias Poaceae, Cyperaceae e Asteraceae se destacaram, provavelmente devido à proximidade das áreas de cultivo e condições edafoclimáticas semelhantes. O clima e o tipo de solo são fatores preponderantes na distribuição das espécies e estrutura das comunidades infestantes no tempo e no espaço (Hereford et al., 2017; Mahgoub, 2019), bem como os métodos de manejo adotado, tipo de cultura e a sua sustentabilidade.

Resultados similares também foram obtidos por Martins et al. (2018), em levantamento fitossociológico realizado na cultura da pimenta-do-reino em pleno florescimento, nas condições do município de Cametá-PA, microrregião do Baixo Tocantins, que também encontraram 34 espécies, sendo às famílias Poaceae e Asteraceae as mais representativas, correspondendo a $32,35 \%$ e $11,76 \%$, respectivamente, do total de espécies.

Moura Filho et al. (2015) também verificaram que a família Poaceae apresentou maior número de espécies de plantas daninhas em cultivo de bananeira irrigada em Ipanguaçu-RN. Além destes trabalhos supracitados, resultados de levantamentos realizados em diferentes locais do país demonstram que Poaceae e Asteraceae se comportam como as principais famílias (Oliveira \& Freitas, 2008; Albuquerque et al., 2012; Albuquerque et al., 2014; Ferreira et al., 2019). Isso ocorre porque uma boa parte das espécies destas famílias produzem grande quantidade de diásporos, o que favorece a disseminação e a ocupação em ambientes diferenciados, mesmo sob condições consideradas desfavoráveis ao crescimento vegetal (Lorenzi, 2008). Da mesma forma, Kissmann \& Groth (1997) relatam que as espécies da família Poaceae são bastante competitivas e altamente agressivas, e ainda podem liberar substâncias alelopáticas no solo, podendo ser prejudicial a várias culturas, principalmente anuais e bianuais.

O baixo percentual de cobertura do solo exercida pela arquitetura dos açaizeiros juntamente com a sua idade (quatro meses) no momento do levantamento, espaçamento de plantio, além de seu crescimento lento (Vieira et al., 2018; Almeida et al., 2019), permitiu uma alta radiação sobre as plantas daninhas, o que pode ter contribuído para a maior ocorrência das espécies monocotiledôneas em relação às dicotiledôneas, já que elas realizam processo fotossintético pela via $C_{4}$. Segundo Taiz \& Zeiger (2017), as espécies $\mathrm{C}_{4}$ são mais eficientes na assimilação liquida de $\mathrm{CO}_{2}$ em temperaturas mais altas, tornando-as mais abundantes nas regiões tropicais e subtropicais.

Em relação ao tipo de propagação, hábito de crescimento e ciclo de vida das espécies ocorridas na área, observou-se as seguintes características: que a maioria das espécies se propagam exclusivamente por sementes (73,53\%) e o restante se reproduz por meio de sementes e rizomas (26,47\%); que a maior parte apresenta duas ou três formas de crescimento, prevalecendo-se o herbáceo ou ereto; e que grande parte possui ciclo de vida anual (47,06\%), seguido de perene $(41,18 \%)$, sendo o restante das espécies anuais ou perenes (11,76\%). Teixeira Júnior et al. (2017), ao realizarem levantamento fitossociológico de plantas daninhas na cultura da mandioca, observaram que a maioria das espécies se propagam por sementes, apresentam hábito de crescimento herbáceo e possui ciclo de vida perene.

Albuquerque et al. (2012), ao realizarem o levantamento fitossociológico de plantas daninhas na cultura do milho em sistema de plantio direto com rotação de culturas na savana amazônica, também observaram que a maior parte das espécies se multiplicam exclusivamente por sementes, possuem hábito de crescimento herbáceo e ciclo de vida anual. Resultados semelhantes também foram encontrados por Albuquerque et al. (2014) ao verificarem a ocorrência de plantas daninhas na cultura da mandioca na savana de Roraima entre janeiro a abril de 2012.

As espécies que apresentaram os maiores índices de densidade absoluta e densidade relativa foram Digitaria sanguinalis, Mollugo verticillata, Murdannia nudiflora, Paspalum conjugatum, Paspalum maritimum e Kyllinga odorata (Tabela 3). Digitaria sanguinalis e Mollugo verticillata tiveram maior representatividade com densidade absoluta de 413 e 205,3 plantas $\mathrm{m}^{2}$, e densidade relativa de $53,1 \%$ e $26,4 \%$, respectivamente. Almeida et al. (2018) também observaram que Digitaria sanguinalis e Mollugo verticillata foram umas das principais espécies de plantas daninhas ocorridas em áreas de bananeira.

Nas condições ecológicas da Amazônia, Vieira et al. (2018) reportam que as braquiárias (Brachiaria spp.) e 
capim carrapicho (Cenchrus echinatus) se constituem como uma das principais espécies de plantas daninhas na cultura do açaizeiro em virtude da boa capacidade germinativa das sementes em diferentes profundidades do solo, principalmente após o segundo ano da implantação. Além disso, os autores recomendam que os açaicultores redobrem os cuidados com o manejo das plantas daninhas no período crítico da lavoura, que ocorre desde o transplantio até o segundo ano de idade, tendo em vista que é uma palmeira que possui sistema radicular denso e superficial, bem como crescimento inicial lento. Com isso, a cultura pode ter o crescimento prejudicado, já que as plantas daninhas tendem a sobressair devido a maior capacidade de competição pelos recursos disponíveis.

A densidade é um dos indicativos da capacidade competitiva e de adaptação das plantas daninhas (Teixeira
Júnior et al., 2017), o que explica a maior quantidade de indivíduos por área destas espécies. A grande capacidade reprodutiva da espécie Digitaria sanguinalis, que produz cerca de 150 mil sementes por touceira (Lorenzi, 2008), aumenta o seu poder de disseminação, além disso é uma planta que realiza fotossíntese pela via $\mathrm{C}_{4}$, o que favorece a sua adaptação em ambiente quente e com alta radiação solar. Essas características podem ter contribuído para a maior densidade tanto absoluta quanto relativa. Entretanto, a planta daninha Mollugo verticillata se adapta bem tanto em ambientes sombreados quanto ensolarados com alta radiação solar devido à fotossíntese ser realizada de forma intermediária $\left(\mathrm{C}_{3}-\mathrm{C}_{4}\right)$. Conforme Lorenzi (2008), $M$. verticillata é medianamente frequente em todos os estados brasileiros, podendo ser encontrada infestando lavouras anuais, pomares, hortas caseiras, dentre outros.

Tabela 3 - Parâmetros fitossociológicos de plantas daninhas em monocultivo de açaizeiro solteiro. Rio Branco-AC, 2014

\begin{tabular}{|c|c|c|c|c|c|c|c|c|}
\hline Espécie & $\left.\mathrm{D}(\mathrm{pl} \mathrm{m})^{2}\right)$ & $\mathrm{DR} \%$ & A & $\mathrm{AR} \%$ & $\mathrm{~F}$ & FR\% & IR\% & IVI \\
\hline Acalypha arvensis & 0,3 & 0,0 & 1,0 & 0,3 & 0,1 & 0,9 & 0,4 & 1,3 \\
\hline Alternanthera tenella & 1,3 & 0,2 & 2,0 & 0,6 & 0,2 & 1,8 & 0,9 & 2,6 \\
\hline Anoda cristata & 0,3 & 0,0 & 1,0 & 0,3 & 0,1 & 0,9 & 0,4 & 1,3 \\
\hline Brachiaria brizantha & 1,3 & 0,2 & 1,0 & 0,3 & 0,3 & 3,7 & 1,4 & 4,1 \\
\hline Brachiaria decumbens & 0,3 & 0,0 & 1,0 & 0,3 & 0,1 & 0,9 & 0,4 & 1,3 \\
\hline Commelina benghalensis & 0,7 & 0,1 & 1,0 & 0,3 & 0,2 & 1,8 & 0,7 & 2,2 \\
\hline Corchorus olitorius & 3,7 & 0,5 & 2,2 & 0,6 & 0,4 & 4,6 & 1,9 & 5,7 \\
\hline Cyperus esculentus & 1,7 & 0,2 & 1,7 & 0,5 & 0,3 & 2,8 & 1,2 & 3,5 \\
\hline Cyperus iria & 1,0 & 0,1 & 1,5 & 0,4 & 0,2 & 1,8 & 0,8 & 2,4 \\
\hline Cyperus spp. & 0,3 & 0,0 & 1,0 & 0,3 & 0,1 & 0,9 & 0,4 & 1,3 \\
\hline Desmodium adscendens & 0,3 & 0,0 & 1,0 & 0,3 & 0,1 & 0,9 & 0,4 & 1,3 \\
\hline Digitaria bicornis & 3,0 & 0,4 & 9,0 & 2,6 & 0,1 & 0,9 & 1,3 & 3,9 \\
\hline Digitaria horizontalis & 2,3 & 0,3 & 3,5 & 1,0 & 0,2 & 1,8 & 1,1 & 3,2 \\
\hline Digitaria sanguinalis & 413 & 53,1 & 123,9 & 35,9 & 0,8 & 9,2 & 32,7 & 98,2 \\
\hline Eleusine indica & 6,7 & 0,9 & 6,7 & 1,9 & 0,3 & 2,8 & 1,8 & 5,5 \\
\hline Emilia coccínea & 3,7 & 0,5 & 5,5 & 1,6 & 0,2 & 1,8 & 1,3 & 3,9 \\
\hline Fimbristylis dichotoma & 6,0 & 0,8 & 3,6 & 1,0 & 0,4 & 4,6 & 2,1 & 6,4 \\
\hline Kyllinga odorata & 11,7 & 1,5 & 17,5 & 5,1 & 0,2 & 1,8 & 2,8 & 8,4 \\
\hline Leptochloa filiformis & 5,3 & 0,7 & 5,3 & 1,5 & 0,3 & 2,8 & 1,7 & 5,0 \\
\hline Lindernia dubia & 19 & 2,4 & 11,4 & 3,3 & 0,4 & 4,6 & 3,4 & 10,3 \\
\hline Malva spp. & 1,3 & 0,2 & 2,0 & 0,6 & 0,2 & 1,8 & 0,9 & 2,6 \\
\hline Mollugo verticillata & 205,3 & 26,4 & 61,6 & 17,9 & 0,8 & 9,2 & 17,8 & 53,4 \\
\hline
\end{tabular}


Tabela 3 - Cont.

\begin{tabular}{lcccccccc}
\hline Espécie & $\mathrm{D}(\mathrm{pl} \mathrm{m})$ & $\mathrm{DR} \%$ & $\mathrm{~A}$ & $\mathrm{AR} \%$ & $\mathrm{~F}$ & $\mathrm{FR} \%$ & $\mathrm{IR} \%$ & $\mathrm{IVI}$ \\
\hline Murdannia nudiflora & 31,3 & 4,0 & 13,4 & 3,9 & 0,6 & 6,4 & 4,8 & 14,3 \\
Panicum maximum & 1,3 & 0,2 & 2,0 & 0,6 & 0,2 & 1,8 & 0,9 & 2,6 \\
Paspalum conjugatum & 15,3 & 2,0 & 23 & 6,7 & 0,2 & 1,8 & 3,5 & 10,5 \\
Paspalum maritimum & 15,3 & 2,0 & 9,2 & 2,7 & 0,4 & 4,6 & 3,1 & 9,2 \\
Paspalum notatum & 0,3 & 0,0 & 1,0 & 0,3 & 0,1 & 0,9 & 0,4 & 1,3 \\
Phyllanthus niruri & 5,0 & 0,6 & 3,0 & 0,9 & 0,4 & 4,6 & 2,0 & 6,1 \\
Phyllanthus tenellus & 1,3 & 0,2 & 2,0 & 0,6 & 0,2 & 1,8 & 0,9 & 2,6 \\
Praxelis pauciflora & 6,3 & 0,8 & 3,8 & 1,1 & 0,4 & 4,6 & 2,2 & 6,5 \\
Pueraria phaseoloides & 3,0 & 0,4 & 2,3 & 0,7 & 0,3 & 3,7 & 1,6 & 4,7 \\
Rhychospora nervosa & 5,7 & 0,7 & 17 & 4,9 & 0,1 & 0,9 & 2,2 & 6,6 \\
Spermacoce latifolia & 2,3 & 0,3 & 1,4 & 0,4 & 0,4 & 4,6 & 1,8 & 5,3 \\
Spigelia anthelmia & 1,7 & 0,2 & 2,5 & 0,7 & 0,2 & 1,8 & 0,9 & 2,8 \\
\hline Total & - & 100 & - & 100 & - & 100 & 100 & - \\
\hline
\end{tabular}

Legenda: $\mathrm{D}=$ densidade absoluta; $\mathrm{A}=$ abundância absoluta; $\mathrm{F}=$ frequência absoluta; $\mathrm{DR} \%=$ densidade relativa; $\mathrm{AR} \%=$ abundância relativa; $\mathrm{FR} \%=$ frequência relativa; IR\% = importância relativa e IVI = índice de valor de importância.

As principais espécies quanto à abundância absoluta e abundância relativa em ordem decrescente foram Digitaria sanguinalis, Mollugo verticillata, Paspalum conjugatum, Kyllinga odorata, Murdannia nudiflora e Lindernia dubia (Tabela 2). Digitaria sanguinalis e Mollugo verticillata se destacaram com os maiores índices de abundância absoluta (123,9 e 61,6) e abundância relativa (35,9\% e 17,9\%), respectivamente. Albuquerque et al. (2012, 2014) também observaram altos índices de abundância absoluta para a espécie Digitaria sanguinalis, nas culturas do milho e da mandioca.

Quanto à frequência absoluta e frequência relativa, as espécies mais representativas foram Digitaria sanguinalis, Mollugo verticillata, ambas com 0,8 e $9,2 \%$, e Murdannia nudiflora com 0,6 e 6,4\%, respectivamente. A elevada frequência relativa destas espécies indica que a ocorrência foi de forma uniforme e bem distribuída em toda área de cultivo, constituindo-se, de forma geral, nas espécies mais importantes devido à alta importância relativa e ao alto índice de valor de importância (Tabela 2; Figura 2) (Ferreira et al., 2019). Martins et al. (2018) observaram que a espécie Digitaria bicornis se sobressaiu frente as demais quanto à frequência absoluta e relativa, a qual está classificada no mesmo gênero de Digitaria sanguinalis. Albuquerque et al. (2014) relataram que Digitaria sanguinalis apresentou o segundo maior índice de frequência absoluta, sendo menor que Commelina benghalensis.
Na Figura 2, pode-se observar as dez espécies principais com maior frequência relativa, abundância relativa, densidade relativa e índice de valor de importância em cultivo de açaizeiro solteiro. As dez espécies principais foram responsáveis por 93,74\% da densidade relativa; 82,46\% da abundância relativa; e 47,72\% da frequência relativa. As espécies Digitaria sanguinalis e Mollugo verticillata se destacaram, apresentando-se os maiores IVI, com 98,2 e 53,4, respectivamente (Figura 2; Tabela 2). O IVI é um parâmetro fitossociológico que indica numericamente a importância de uma determinada espécie dentro do ambiente que foi realizado o levantamento da comunidade infestante (Teixeira Júnior et al., 2017; Almeida et al., 2018).

Em estudo fitossociológico realizado na cultura do milho em plantio direto com rotação de culturas por Albuquerque et al. (2012), observou-se que os maiores IVI foram de Cyperus rotundus e Brachiaria humidicula, e que a espécie Digitaria sanguinalis foi quarta com maior índice. Albuquerque et al. (2014) também relataram que a espécie Digitaria sanguinalis apresentou o maior IVI devido aos elevados índices de DR\%, AR\% e FR\%, seguido de Brachiaria brizantha e Brachiaria decumbens. Esses resultados são similares ao do presente estudo, já que a planta daninha mais importante da área de estudo, ou seja, com maior IR\% e IVI, pertence à classe das monocotiledôneas, cuja adaptação, crescimento e 
desenvolvimento é mais favorável em ambientes quentes e com alta radiação.

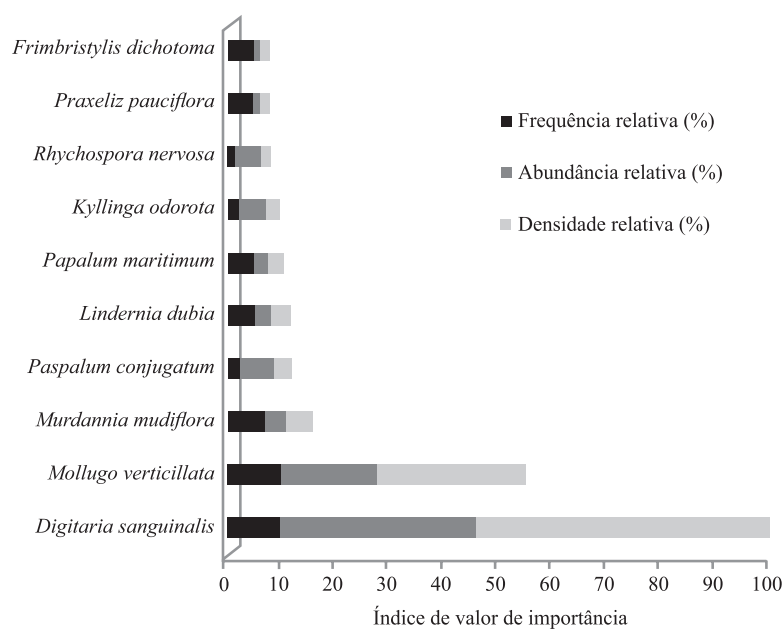

Figura 2 - Índice de valor de importância das dez espécies de plantas daninhas mais relevantes ocorridas em monocultivo de açaizeiro solteiro. Rio Branco-AC, 2014.

As informações referentes à biologia das espécies de plantas daninhas que ocorrem nas culturas exploradas economicamente, seja anual ou perene, como o meio de propagação, ciclo de vida, hábito de crescimento, tipo de folha (larga ou estreita), distribuição e populações dentro do cultivo são informações essenciais aos produtores, as quais auxiliam no planejamento de estratégias preventivas para a tomada de decisão quanto ao método de controle mais eficiente (isolado ou integrado), econômico e sustentável (Albuquerque et al., 2012; Teixeira Júnior et al., 2017; Almeida et al., 2018). Dessa forma, o açaicultor pode evitar a dispersão de espécies consideradas agressivas dentro da área de cultivo por controlá-las no momento certo e de forma eficaz, a exemplo da principal planta daninha que ocorreu neste estudo (Digitaria sanguinalis) que possui grande capacidade reprodutiva.

\section{CONCLUSÕES}

As principais famílias que ocorreram em cultivo de açaizeiro solteiro foram Poaceae, Cyperaceae e Asteraceae.

A maioria das espécies observadas pertencem a classe das monocotiledôneas, propagam-se por sementes, apresentam hábito de crescimento herbáceo e ciclo de vida anual.
As espécies mais importantes foram Digitaria sanguinalis e Mollugo verticillata, pois se destacaram em todos os parâmetros fitossociológicos analisados.

\section{LITERATURA CITADA}

ALBUQUERQUE, J.A.A.; EVANGELISTA, M.O.; MATES, A.P.K.; ALVES, J.M.A.; OLIVEIRA, N.T.; SEDIYAMA, T.; SILVA, A.A. Occorrence of weeds in Cassava savana plantations in Roraima. Planta Daninha, v.32, n.1, p.91-98, 2014.

ALBUQUERQUE, J.A.A.; MELO, V.F.; SIQUEIRA, R.H.S.; MARTINS, S.A.; FINOTO, E.L.; SEDIYAMA, T.; SILVA, A.A. Ocorrência de plantas daninhas após cultivo de milho na savana amazônica. Planta daninha, v.30, n.4, p.775-782, 2012.

ALMEIDA, U.O.; ANDRADE NETO, R.C.; LUNZ, A.M.P.; TAVELLA, L.B.; MARINHO, T.S.; NOGUEIRA, S.R. Ocorrência de plantas daninhas em cultivo de bananeira comprida em diferentes espaçamentos no Estado do Acre. South American Journal of Basic Education, Technical and Technological, v.5, n.1, p.188-203, 2018.

ALMEIDA, U.O.; ANDRADE NETO, R.C.; CADES, M.; GOMES, R.R.; SANTOS, R.S.; LUNZ, A.M.P.; COSTA, D.A.; ARAUJO, J.C.; ARAUJO, J.M. Crescimento e rendimento de bananeira consorciada com açaizeiro (Euterpe precatoria L.). South American Journal of Basic Education, Technical and Technological, v.6, p.95-106, 2019.

CARMO, C.L.M.; PARREIRA, M.C.; MARTINS, J.S.; RIBEIRO, R.C.; SILVA, E.M. Fitossociologia das plantas daninhas na cultura do bacuri (Platonia insignis Mart.) na Amazônia Oriental. Revista Brasileira de Agropecuária Sustentável (RBAS), v.9, n.1, p.47-55, 2019.

CEDRIM, P.C.A.S.; BARROS, E.M.A.; NASCIMENTO, E.G. Propriedades antioxidantes do açaí (Euterpe oleracea) na síndrome metabólica. Brazilian Journal of Food Technology, v.21, e2017092, p.1-7, 2018.

FERREIRA, E.A.; PAIVA, M.C.G.; PEREIRA, G.A.M.; OLIVEIRA, M.C.; SILVA, E.B. Fitossociologia de plantas daninhas na cultura do milho submetida à aplicação de doses de nitrogênio. Revista de Agricultura Neotropical, v.6, n.2, p.100-107, 2019.

HEREFORD, J.; SCHMITT, J.; ACKERLY, D.D. The seasonal climate niche predicts phenology and distribution of an ephemeral annual plant, Mollugo verticillata. Journal of Ecology, v.105, p.1323-1334, 2017. 
KISSMANN, K. G.; GROTH, D. Plantas infestantes e nocivas. São Paulo: BASF Brasileira, v.2, 1997. 798p.

LORENZI, H. 4 ed. Plantas daninhas do Brasil: terrestres, aquáticas, parasíticas e tóxicas. Nova Odessa: Instituto Plantarum, 2008.

MAHGOUB, A.M.M.A. The impact of five environmental factors on species distribution and weed community structure in the coastal farmland and adjacent territories in the northwest delta region, Egypt. Heliyon, v.5, n.4, p.1-33, 2019.

MARTINS, M.P.; MARTINS, J.S.; PARREIRA, M.C.; SOARES, J.B.C.; RIBEIRO, R.C. Levantamento fitossociológico de plantas daninhas na cultura da pimentado-reino na Amazônia Oriental. Revista Brasileira de Agropecuária Sustentável, v.8, n.3, p.91-98, 2018.

MELO, M.F. Capacidade competitiva de goiabeira $e$ plantas daninhas na fase inicial de crescimento. 2018. 47f. Dissertação (Mestrado em Fitotecnia) - Departamento de Ciências Vegetais, Universidade Federal Rural do SemiÁrido, Mossoró, 2018.

MOURA FILHO, E.R.; MACEDO, L.P.M.; SILVA, A.R.S. Levantamento fitossociológico de plantas daninhas em cultivo de bananeira irrigada. Holos, v.2, n.31, p.92-97, 2015.

OLIVEIRA, A.R.; FREITAS, S.P. Levantamento fitossociológico de plantas daninhas em áreas de produção de cana-de-açúcar. Planta Daninha, v.26, n.1, p.33-46, 2008.
TAIZ, L.; ZEIGER, E. Fisiologia e desenvolvimento vegetal. 6. ed. Porto Alegre: Artmed, 2017. 858p.

TEIREIXA JUNIOR, D.L.; BARILI, M.E.; ALBURQUERQUE, J.A.A.; SOUZA, F.G.; CHAVES, J.S.; MENEZES, P.S.S. Fitossociologia e características botânicas de plantas daninhas na cultura da mandioca. Revista Sodebras, v.12, n.138, 2017.

VIEIRA, A.H.; RAMALHO, A.R.; ROSA NETO, C.; CARARO, D.C.; COSTA, J.N.M.; VIEIRA JÚNIOR, J.R.; WADT, P.G.S.; SOUZA, V.F.S. Cultivo do açaizeiro (Euterpe oleracea Martius) no Noroeste do Brasil. Porto Velho: Embrapa Rondônia, 2018, 90p. (Sistema de produção, 36).

WITTER, A.P.W.; NOHATTO, M.A.; BORGES, B.L.; KASEKER, J.R.; ROSA, E.F.F.; MADEIRA, L.G.; FERMIANO, A.P. Fitossociologia e supressão de plantas daninhas sob efeito da solarização e cobertura com capimelefante. Revista Brasileira de Agropecuária Sustentável (RBAS), v.9, n.1, p.53-63, 2019.

YUYAMA, L.K.O.; AGUIAR, J.P.L.; SILVA FILHO, D.F.S.; YUYAMA, K.; VAREJÃO, M.J.; FÁVARO, D.I.T.; VASCONCELOS, M.B.A.; PIMENTEL, S.A.; CARUSO, M.S.F. Caracterização físico-química do suco de açaí de Euterpe precatoria Mart. oriundo de diferentes ecossistemas amazônicos. Acta Amazônica, v.41, n.4, p.545-552, 2011.

Recebido para publicação em 27/05/2019 e aprovado em 02/09/2019. 